\title{
The Global Crisis and Its Role in the Formation and Development of Human Thinking
}

\author{
Elena Pavlova ${ }^{1 *}$ and Irina Paliy ${ }^{1}$ \\ ${ }^{1}$ Rostov State University of Economics (RSUE), Faculty of trade, Russia.
}

\begin{abstract}
.
Research background: The modern world is situated today in a very difficult and complicated period of existence: the coronavirus pandemic, quarantine, the global lockdown, etcetera. Today we are talking about the transition to a new type of social structure, and this transition to something new always entails complexity in adaptation and some breaking of familiar stereotypes. The mankind has faced again the necessity to develop new norms.

Purpose of the article: In this article, from the point of view of philosophy, one of the most complex phenomena of the modern information age, is characterized, namely: the global crisis and its role in the formation and development of human thinking, is studied and analyzed. The author's position echoing the key philosophical ideas presented by such philosophers as R. Descartes and B. Spinoza, I. Kant and G. Hegel, V. Heisenberg and by the others, however, contains its own authorial position. Methods: As part of the historical-comparative analysis, the crucial cultural and existential problems in modern society are demonstrated. The analysis is presented through the prism of such phenomena as a conflict of values, the subjective experience of a person, and a crisis.

Thanks to an extensive historical-philosophical and sociocultural discourse, the main milestones of the transformation of understanding and attitude of a person to the basic existential elements of his being in a crisis situation are shown.

Findings \&; Value added: The main focus of the article is on the study and new reception of some previous views on the phenomenon of crisis and the role of philosophy in its evolution.
\end{abstract}

Key words: crisis; conflict of values; subjective reality; personality; worldview

JEL Classification: $D 83 ; F 01 ; I 18$

"Corresponding author: pavlova@philosophical.ru, 


\section{Introduction}

The modern world is firmly connected with the phenomenon of globalization. In fact, globalization means a new stage in the historical development of society, where the economic, political and cultural interaction of the countries of the modern world is becoming more intense and profound. Obviously, this new stage of our human history must be extremely complex and with internal contradictions.

It is no coincidence that the current state of globalization is a combination of the independent development of individual states and societies, on the one hand, and the inevitable integration processes between them, on the other. The problem of understanding of crisis, and its role in the modern society is one of the most important factors for ensuring the stability of the modern existence of mankind.

We have been talking about crisis for more than twenty years in Russia. In the doctor's degree dissertations, research monographs, the term «crisis» and everything that is associated with it is used as an obligatory component of the relevance.

Today, in fact, many of the concepts and categories lose their informative value. The mankind has faced again the necessity to develop new norms. «Drastic changes in the socio-cultural life clearly force to realize more accurately those cultural norms and values that go into the past, to compare them with the new ones that emerge directly and spontaneously [1].

On the other hand, the collision of two value systems, old and new, leads to the emergence of the phenomenon which in cultural anthropology is called «culture shock». Its essence lies in the sharp conflict of old and new values, orientations and ideals, norms of behavior at level of the individual consciousness when a person loses his life orientation [2].

Over the past fifteen years, about one hundred revolutionary discoveries have been made in all spheres of science.

The Higgs boson discovery, decoding of the human genome, a total artificial heart, an artificial retina, neuroprosthetics, tablets, smart dust, dynamic architecture, flexible solar panels, a head-mounted display, a projection keyboard, digital cameras in mobile phones, digital scent synthesizers, e-cigarettes, smart chopsticks - even one of the abovementioned inventions seemed unachievable fifty years ago.

Eventually medicine has managed to cure the major communicable diseases; surgery has reached great results in organ transplantation. Modern technologies enable laser-beam operations, computer-assisted wellness screening. New pharmaceutical drugs are being constantly developed. Modern technologies help create more natural medical drugs [3;4].

European Convention on Human Rights established people's fundamental rights and freedoms more than fifty years ago.

Thus, we are observing a superficially paradoxical situation. On the one hand, from the worldwide point of view, our society as a whole is developing in leaps and bounds, showing progress in every sphere it has to do with. But on the other hand individual people, being part of this society, are suffering from extreme problems with health, work, elementary literacy $[5 ; 6]$.

But we are continuing to discuss the problem of a crisis stage in the modern reality/ Why? In that article we are going to realize that matter.

\section{Methodology}

Theoretical interpretation of the definiion of the term "the crisis" in the context of globalization requires an integrated approach. 
A big number of social processes, which modern science calls "globalization", poses a number of problems not only for researchers and theoretics, but politicians and experts of all kinds as well. The researchers are paying more and more attention to the processes connected with globalization and international meetings of the leaders of different countries often have globalization issues in their agenda [7].

If one understands the methodology as a kind of "key" necessary for an adequate discovery, not for hacking the "door" - of a problem, then the importance and necessity of creating and building a clear methodological complex within the framework of the existing problem of globalization becomes evident.

The method of temporal analysis and the method of personalistic and ideal-typical reconstruction, a tool that is adequate to the author's interpretation of the phenomen of a modern crisis in the era of globalization as a process of constituting the temporal and ethical dominance of individuals and collectivities that formalize the integrity of the cultural epoch, will become the immediate, applied methodological basis [8].

\section{Results}

\subsection{The problem of definition of crisis in the history of philosophy and economy}

The Russian scientists, believe that «... it is possible to talk about the breaking of an «era of crises», associated with the acceleration of the socio-cultural development, increasingly growing complex differentiation of the various spheres of the social life. As a result, the identity of the person with himself and the unity of the culture are lost [9].

In this definition we were especially interested by two moments: «the sharp conflict of old and new values», and also the loss by the person of «life orientation». We will try to understand these moments and to offer our own vision of the given situation.

One of the Russian economists, V. Visokov in his article «How to survive the crisis?», writes that very often «... by means of crisis the economy overcomes the limitation of some resources and their replacement with the others for the reproduction restoration. However, such reproduction starts to have a little bit of a cyclic character, but each slowdown is only a signal for changing the development model. The one, who will be the first to find a variant of such model, gets competitive advantages but already in new market conditions» $[10]$.

So, what do we observe? We see that the crisis can be understood at least in two ways: as the negative moment associated with the «culture shock» and loss of orientation in this world, and on the other hand - as the positive moment contributing to the development of a new development model.

However, for the most part, in our opinion, the relation to the crisis for many people has a negative character. It is often difficult, impossible for the people to accept in their life something new. Why?

\subsection{The problem of mythological thinking in the modern human culture}

Our thinking in many respects is still mythological. Let us recall that in the natural myths the initial role is carried out by the attitudes which allow to realize the world on the basis of live contemplation and sanity. For the ordinary attitudes is always characteristic the subconscious reduction of all reality to the part which is available in the direct form reflecting only the surface, the evidence of the things, without getting into their essence and laws [11]. 
Therefore the mythology forms the mosaic picture of the world consisting of the separate myths-fragments between which there are considerable voids. The latter, in turn, require some kind of intuitive filling, superstitious fantasy, irrational interpretation. As a result, the mythological picture of the world is confronted with the necessity to combine the reflected reality with fantasy, illusion and imagination. Owing to this mythologization, we explain the world, taking as an explanation the very first reason lying on a surface of our consciousness.

It is known that a person has a very small volume of the operative memory, trying to transfer faster the important and significant events for himself to the long-term memory. When we are in an uncertainty situation for a long time, when we lack confidence in the objectivity, adequacy of the knowledge which we get from the outside world, we experience stress and discomfort. When we are in a situation when we can't solve new problems in the old ways anymore, when there is a conflict of new and old values, that's when we start talking about the crisis [12].

Certainly, mythological layers of our consciousness have incredible stability and extensiveness. Today we will only tell that these layers were formed in parallel with the development and evolution of the human community, having played a considerable role in the formation development of almost all institutes of a modern civilization [13].

The philosopher - it is really, in the apt words of Hegel, «the voice of his epoch», and the philosophy reflects today the problems of the present reality. Obviously, in the consciousness of the people there is actually the concept of crisis if the philosophers talk about it in their works. But why? We know that the outlook of the people is formed under the influence of the most various circumstances: education, upbringing, life experience, individual life experiences. Living conditions, epoch general features, national features of culture affect it. Outlook development tools are philosophical reflections. In the systems created by the philosophers are generalized and rationalized the various variants of world outlook attitudes and beliefs that people have. Therefore, the ideas of the philosophers receive recognition and acceptance in society. Thus, philosophy - means of expressing, organizing and substantiation of the outlook, a theoretical basis for solving world outlook problems.

In the minds of some people, philosophy - is abstract-abstruse reasoning which has nothing to do with the practical needs and affairs of the person. But after all, the philosophy history has its heroes and martyrs that testifies its direct and close connection with the social practice and consequently plays a huge role in a society, in the formation of the human personality.

Our deep belief, that the modern philosopher today can no longer be isolated in the narrow field of the specialization. In the modern world of globalization and continuously evolving information technologies, we can't be «one-dimensional» workers from philosophy anymore.

\subsection{A social crisis and the structure of a human consciousness - the problem of the connection}

We believe that the issue of the modern crisis is very closely connected with a question on (as paradoxical at first glance it may sound) how the brain and consciousness correspond with each other. How on the basis of the nervous impulses the subjective world of the person is formed? Psychophysiological parallelism of Descartes, Spinoza's substance, Kant's transcendental unity of apperception... We know that for a long time this problem was considered as a field of studies of philosophy and other humanitarian disciplines. And only in last decades, the natural-science approaches to its solution have been discovered. 
By the modern psychophysiologists it is proved that «... the subjective experience results from the certain organization of the brain processes and comparison in the areas of the cortex of the newly received information with the retrieved one from the memory. Due to this, the picture of the external events is as though projected on the individual experience of the subject, incorporating in a personal context» [14].

One of the most influential psychophysiologists of the modern scientific world, A. Ivanitsky, has proved in his numerous works that the formation of the structures of our thinking takes place in layers, in rigid dependence on the course of the evolutionary process (always associated with the stress and crisis, notice!) where the most ancient structures, are simultaneously the most inert, stiffened, and the new, gradually formed structures of thinking - the most flexible, most unstable and dynamic. And, at the time of the stressful situations, the situations involving the conflict between the old and new system of values, the situations of inability to achieve an effective solution to the problem, these ancient, primitive and mythological structures become more active.

Why have we been talking so much and for so long about the crisis? Why have we been haunted by the «Russian idea» for so many centuries in a row? Perhaps, the old structures of our thinking can no longer reflect the rapidly changing world anymore? Perhaps we feel, yet at the intuition level, the developed contradiction between our traditional way of thinking and the real life, or rather, with the requirements that it imposes? How many times do we carefully build a strategy of our behavior, considering, as it would seem, all the little things, and suddenly, everything falls apart because of the unpredictability of the world, life, other person?

It is obvious that the old mechanisms of an explanation of the world and the person don't work anymore. What does it mean? It means that people have lost adequate communications with the outside world and other people, that is the new realities of the world (such as globality, tolerance, cosmopolitism - the properties necessary in the modern world for a comfortable existence) don't work for those people who have got used to rely on the old (the most ancient, generated by the thousands of years, standard and stereotyped) structures of the thinking.

Therefore, probably, we are indeed in a transitive, very complicated and difficult period of existence - after all, the transition to something new, always implies the difficulty in adapting and breaking the traditional stereotypes [15].

If we can get the maximum benefit out of this crisis about which we have been talking for so many years, in parallel with this, we will also resolve a lot of the world outlook issues, including the sacramental issue «about the Russian idea».

\section{Discussion}

The work adjoins the main thematic areas developed within the domestic and foreign schools dealing with the phenomenon of social and economical crisis in modern society and is the result of many years of the author's work on the problems of theory, practice and methodology of socio-philosophical problems of culture and society.

The discussion nature of the work is related to the specifics of its object, object and purpose and is determined by the nature of its tasks. The work is aimed at systematization, deepening and refining of modern philosophical knowledge about the essence of social crisis in modern Russia and in the modern world on the whole in the conditions of globalization. 


\section{Conclusion}

We believe that one of the primary goals of the modern philosophy is the search for the new world outlook model, a model that will help us to form the new relation to ourselves, other people and the world around us.

We have already said that the modern philosopher cannot become isolated within the limits of his own, philosophical-sacral specialization. In support of this idea, it would be desirable to quote one of the great physicists of our time, who presented his understanding of how the new views come to a science. These thoughts, we believe, may be of interest for the representatives of other spheres of activity. Heisenberg has offered a beautiful explanation of how it occurs:

«The one who tries to change as little as possible can count on success only, showing by this that the changes are compelled by the subject itself, and those small changes which absolute necessity the scientist finally proved, then force to change the thinking structure, that is to make fundamental changes...» [16].

In other words, says Heisenberg, one should begin with that concrete that is at hand. Polish it, revealing the tiniest nuances, features, details. Struggle to apply the available knowledge. And show from the different sides, not through the individual and diverse examples, where it is absolutely necessary to abandon the traditional representations.

In our opinion - the problem of the modern theoretical (philosophical, first of all) thinking, is not only in the reflection of the reality, but in its (reality) maximum «advancement».

Newton noticed at the time that he was «the dwarf» standing on the shoulders of titans and consequently he sees further than these titans. We have the richest philosophical heritage which is presented by the myriad of possible philosophical schools, movements and directions. We can, by basing on this heritage, form the new outlook, help people to overcome the contradiction existing in their consciousness between their thoughts and the outside world. In the fifth century B.C., the greatest wise man lived in the Ancient Greece, who outlined the possibilities of our knowledge. He once said: «I know that I know nothing, but let's try to reflect on it together».

We have to emphasize, that our society is constantly self-improving. It happens so because there are some defects in the society that prevent people from living comfortably. The society, socialization are the most necessary things in life of any person. But development of a society occurs today without direct participation of people. Neither progress nor a developing society depend on a separate person. However, society progress is obvious - the state, ideologies, process of welfare [17].

Yes, our knowledge is imperfect and one cannot square the circle. But the man would not be the man if he didn't aspire to the impossible. To learn and understand the unknown, to improve the knowledge are the goals for which one should live and which presence distinguishes us from animals [18].

The understanding, according to famous German philosopher Gadamer, for example, is not the act of the mental operation but only a reason to reflect on the text, in which the selfaffirmation of the interpreter is carried out. In the course of the Meeting with Another (with a capital letter because this is an ontological meeting) is formed "You-experience». This understanding is the basis of the human activity and even of the life in general precisely because in the dialogue, the real sense formation is born [19].

For example, if you see in a work of art a concrete game according to the certain rules and at the same time recognize for it such a fundamental role, as it follows from the statements of Y. M. Lotman, in this case the whole culture can be presented as an allencompassing game of colossal volume and significance, in which huge human communities take part, finding in it the form and meaning of existence $[20,21]$. 
And so, Socrates, in our opinion, has found his own way to comprehend the truth. He rejected the statement that the truth is born in the dispute and opposed the dialogue to the dispute. We should put ourselves in the place of the interlocutor and together with him pass the whole thorny path. Socrates was having conversations with the ordinary people and discussing problems that concerned them. This enabled him to be enriched with the knowledge of the interlocutor and solve complex problems without antagonism and hatred. Dialogue, instead of dispute, a conversation with the person, not with the crowd - that's the secret of Socrates. Dialogue, in our opinion, is the first and necessary tool in this long and thorny path of finding a new model of the outlook.

\section{References}

1. Shtompel' L. A., Konstantinova T. V. (2010). Vremja kul'tury i temporal'nyj nigilizm. Formy i smysly vremeni. Sbornik nauchnyh trudov. Russia, 399-408.

2. Alexandrova, A. (2018). Can the science of well-being be objective?. The British Journal for the Philosophy of Science, 69(2), 421-445.

3. Walter, N., \& Tukachinsky, R. (2020). A meta-analytic examination of the continued influence of misinformation in the face of correction: how powerful is it, why does it happen, and how to stop it?. Communication Research, 47(2), 155-177.

4. Parry, B. (2018). The social life of "scaffolds" examining human rights in regenerative medicine. Science, Technology, \& Human Values, 43(1), 95-120..

5. I. Paliy, H. Pavlova, (2017). Global society of the XXI century: self-organization or self-destruction? The problem of collective intelligence in the evolution of human culture and civilization. 17th International Scientific Conference Globalization and Its Socio-Economic Consequences University of Zilina, The Faculty of Operation and Economics of Transport and Communications, Department of Economics 4th - 5th October 2017, 1890-1896.

6. Sizemskaya, I. (2018). Welfare State and Civil Society: The Lines of Coupling in the Conditions of Modernization Transformation. Russian Journal of Philosophical Sciences, 2, 44-49.

7. Zimovets, S. (2016). One Shade of Facebook. Logos, 26 (6), 3-19.

8. Shchedrina, T. G. (2018). The Problem of Understanding of Historical Reality (Gustav Shpet's Methodological Experience). Voprosy filosofii, (12), 90-93.

9. Marinosyan, H.A. (2017). The social revolution in the context of challenges of globalizing modernity. Russian Journal of Philosophical Sciences, 1, 7-22.

10. Visokov, V. (2009). Southern Russia Versus the Global Crisis. Russia, 35-41.

11. Shtompel', O.M. (2014). Sociokul'turnyj krizis i vozmozhnye puti vyhoda iz nego. Nauchnaja mysl' Kavkaza, 3(79), 45-53.

12. Huntington, S. P., \& Jervis, R. (1997). The clash of civilizations and the remaking of world order. Finance and Development-English Edition, 34(2), 51-51.

13. Zizek, S. (2013). The clash of civilizations in a single country. Logos, 93(3), 55-74.

14. Ivanitsky, A. (2006). Physiological basis of consciousness and artificial intelligence problem. Artificial intelligence. The interdisciplinary approach. Under D.I. Dubrovsky and V.A. Lektorsky's edition, Russia.

15. Bechtel, W. (2019). Analysing network models to make discoveries about biological mechanisms. The British Journal for the Philosophy of Science, 70(2), 459-484.. 
16. Heisenberg, W. (1962). Physics and Philosophy: The Revolution in Modern Science Harper \& Row, 197.

17. Shoemaker, S. (2016). Self-Knowledge for Humans. Philosophical Review, 125(4), 589-592.

18. Lvov, A. A. (2020). Anthropological turn in worldview studies: Theoretical and practical aspects. Vestnik of Saint Petersburg University. Philosophy and Conflict Studies, 36(2), 279-290.

19. Marinosyan H.A. (2016). New strategy of national states in the context of globalization. Russian Journal of Philosophical Sciences. 2(10), 7-27.

20. Porus, V. N. (2016). What Does It Mean to" Understand" a Literary Text?. VOPROSY FILOSOFII, (7), 75-84.

21. Gryakalov, A. A. (2020). Philosophical Congresses:Understanding and WitnessSubject. Voprosy Filosofii, 11, 77-81. 